(C) Kulesh P.N., Solomin L.N., 2021

DOI 10.18019/1028-4427-2021-27-3-390-397

\title{
Relationships between reference lines altered during leg shape correction as requested by the patient
}

\author{
P.N. Kulesh ${ }^{1}$, L.N. Solomin ${ }^{2,3}$ \\ ${ }^{1}$ City Hospital of St. George the Great Martyr, Saint Petersburg, Russian Federation \\ ${ }^{2}$ Vreden National Medical Research Center of Traumatology and Orthopedics, Saint Petersburg, Russian Federation \\ ${ }^{3}$ Saint-Petersburg State University, Saint Petersburg, Russian Federation
}

\begin{abstract}
Introduction Patients who want their leg shape changed often identify the O- or X-shaped legs with varus or valgus deformity striving for ideally shaped legs as classified by A. A. Artemiev. The purpose of the study was to compare changes in the relationship between reference lines as mechanical axis deviation (MAD), mechanical medial proximal tibial angle (mMPTA), mechanical lateral distal tibial angle (mLDTA) and the associated duration of the correction (CP), fixation (FP) and frame-on periods (FoP) in patients who underwent correction to have the legs shape as requested and those who underwent tibial deformity correction. Material and methods There were 43 patients ( 84 segments operated on) in the cosmesis group and 15 participants ( 28 segments operated on) in orthopedic group. Preperative MAD, mMPTA, mLDTA measured $17.48 \pm 1.14 \mathrm{~mm}$ medially, $84.90 \pm 0.35^{\circ}$ and $90.61 \pm 0.39^{\circ}$ in the cosmesis patients; $19.18 \pm 2.86 \mathrm{~mm}$ medially, $84.04 \pm 0.35^{\circ}, 89.09 \pm 0.37^{\circ}$ in orthopaedic patients with no statistically significant differences observed between the groups. Results CP, FP and FoP lasted for $41.93 \pm 3.96,97.67 \pm 7.78$ and $139.60 \pm 5.15$ days in the cosmesis group, and $18.22 \pm 3.05,134.89 \pm 9.42$ and $153.00 \pm 8.49$ in controls. FP/CP, CP/FoP, FP/FoP measured $0.57 \approx 1 / 2,0.31 \approx 1 / 3,0.69 \approx 2 / 3$ in the cosmesis group and $0.15 \approx 1 / 7 ; 0.12 \approx 1 / 8 ; 0.88 \approx 7 / 8$ in controls. MAD, mMPTA, mLDTA measured $6.08 \pm 0.87$ mm laterally, 90.80 $\pm 0.31^{\circ}, 88.62 \pm 0.35^{\circ}$ in the cosmesis participants, and $0.61 \pm 0.82 \mathrm{~mm}$ laterally, $89.46 \pm 0.54^{\circ}, 87.68 \pm 0.63^{\circ}$ in controls. Discussion There were no statistically significant differences in FoP with different duration of $\mathrm{CP}(\approx 1 / 3 \mathrm{FoP}$ for the cosmesis group and $\approx 1 / 8 \mathrm{FoP}$ for controls). The means of MAD, mMPTA of measured up to tibial valgus in cosmesis patients and were well within acceptable limits of normal in controls. Tibial valgus was caused by too much overcorrection (by $1 / 4$ on average).

Keywords: tibial deformity, deformity correction, correction of leg shape, O-shaped leg
\end{abstract}

\section{INTRODUCTION}

Patients who seek advice about leg correction surgery often have a vague idea of tibial varus and valgus deformities and how to treat them surgically. The most common way of getting the information is to use freely available websites on the Internet with thematic categories [1-3]. Most of the sites do not have the official status of assigned medical organizations, therefore, posts containing false information cannot be the subject of violation of the rights of citizens in the field of health protection [4]. Neither the person's identity with the resources nor his/her legal capacity and competence can be established ${ }^{1}$. The lack of expert control over the posted judgments and the reliability of the information misleads leg lengthening candidates [5-8].

The legs can be "ideally" shaped, O-shaped ("true and false curvature") and X-shaped as classified by A.A. Artemyev [5]. Most patients are misguided to identify the $\mathrm{O}$ - or $\mathrm{X}$-shaped legs as varus or valgus deformity of the lower limbs [9-12], and ideally aligned legs are deemed those having no signs of lower limb deformity according to the classification of the above author. These views have been refuted by the author of

\footnotetext{
The text concerning the legal aspects was prepared jointly with the staff lawyer of GBUZ "GB St. Great Martyr George" V.G. Rakhmin.
}

the classification [5] and other orthopaedic surgeons [6$8,13]$. There are also freely available programs on the internet which are incorrectly presented as "planners" of operations for correcting tibial osteotomies based on photographs of the legs without the use of long leg standing anteroposterior radiographs (for instance, the Legscorrection 1.0 program [14], "OrthoCosmetologist" [15] and "Leg Shape Correction" software [11]). The purpose of the deformity correction is to normalize the relationship between the reference lines and simultaneous limb length equalization if needed [9-11]. The leg shape other than "ideal" shows no signs of the deformity [7-12]. Preoperative planning with long leg standing anteroposterior radiographs can be performed using applications or graphic editors [912, 16-18], specialized licensed software developed for orthopedic surgeons (for example, TraumaCad, Bone Ninja, OrthoView) $[8,19,20]$.

The purpose of the study was to compare changes in the relationship between reference lines and the associated duration of the correction, fixation and frame-on periods in patients who underwent correction to have the legs shape as requested and those who underwent tibial deformity correction. 


\section{MATERIAL AND METHODS}

The duration of the treatment stages and long leg standing anteroposterior radiographs of patients who underwent tibial deformity correction were reviewed. Tibial deformity was identified in the coronal plane with measurements of the mechanical medial proximal tibial angle (mMPTA) and mechanical lateral distal tibial angle (mLDTA). Preoperative planning was performed with the technique similar to that developed by P. Lobenhoffer [18]. The planning included transverse osteotomy at a distance of 7-9 cm distally from the midnorch of the intercondylar eminence; remodeling of the distal shift (angulation in the frontal plane) to MAD $=0 \mathrm{~mm}$. The level of the tibial osteotomy is determined by the anatomy measuring $1-2 \mathrm{~cm}$ distal to the tibial tuberosity to avoid injury. The mMPTA and the mLDTA were measured as predicted values after planning. If the measurements did not correspond to the normal values, preoperative planning of the level and number of osteotomies was performed according to the method offered by D. Paley [9]. Circular external fixation devices with wire and half-pins were used to fix the bone $[10,11]$. Postoperative correction was performed gradually using hinges $[9-11,21]$.

The study did not include patients who developed complications that required additional surgical interventions (category II and III complications as classified by J. Caton (SoFCOT) [22], categories "obstacles" and "complications" as classified by D. Paley [23], categories II, III and IV according to the classification of L.T. Donnan [24]). The classifications were originally developed to evaluate complications that patients could develop during limb lengthening and could be employed for adverse events that occurred during deformity correction [25]. 43 patients (84 operated segments) who showed no compliance with the recommendations provided by the orthopaedic surgeon, produced correction and completed it after obtaining the leg shape as wanted (Fig. 1 a-d). These patients comprised a "cosmesis" group.

The leg shape achieved was evaluated by patients using a five-point Marker-Sklyar system [6] modified by Kulesh and Solomin [7] with the outcomes scored 5 to 1 ("5" indicated complete satisfaction with surgery; "4" indicated satisfaction of the patient who might plan an additional operation in the indefinite future; " 3 " indicated dissatisfaction with surgical treatment with no plans for repeat surgery; "2" indicated dissatisfaction with surgical outcome and plans for a repeat operation in the near future or the patient has been re-operated; "1" indicated a re-operation due to impaired supportability of the limb/nonunion/tibial malalignment). The subjective satisfaction score in this group of patients averaged to $4.51 \pm 0.08$ (scored 5; $n=22$; scored $4(n=21)$. Patients who failed to achieve the leg shape as wanted with satisfaction scored 3 points and below were not included in the study. 15 patients (28 operated segments) demonstrated compliance and could accomplish tibial deformity correction forming an "orthopaedic" control group. The correction terminated as soon as the deformity appeared to be corrected (Fig. 1 e-h).

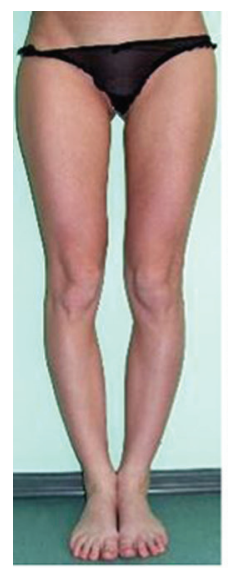

a

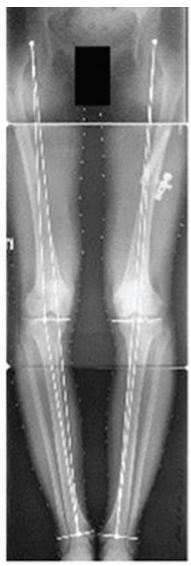

b

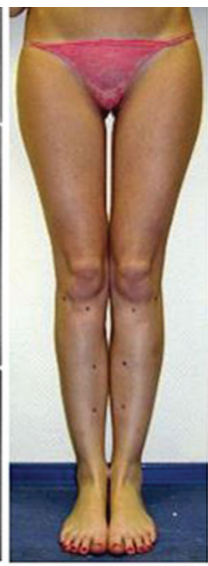

C

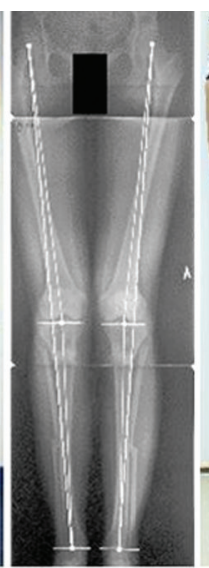

d

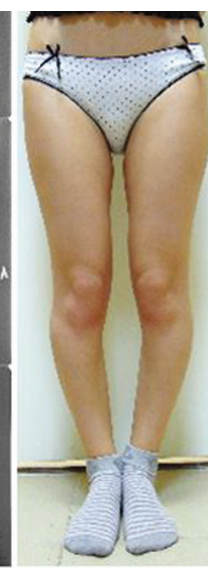

e

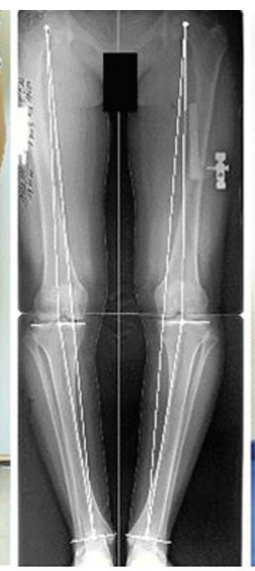

f

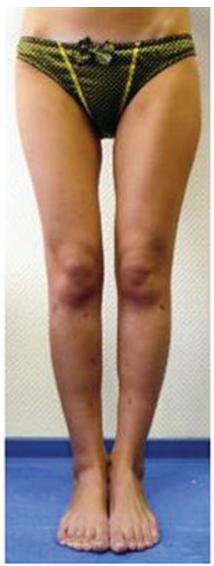

q

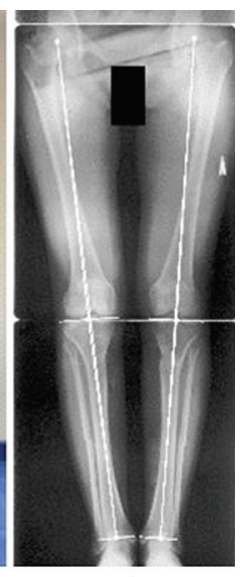

$\mathrm{h}$

Fig. 1 Photographs of patients' legs showing $(\boldsymbol{a})$ preoperative appearance of the O-shaped legs from cosmesis group as classified by A.A. Artemyev; $(\boldsymbol{b})$ preoperative long-leg standing AP film of the same patient with reference lines being beyond the acceptable limits of normal measuring MAD $\left.(\mathrm{D} / \mathrm{S})=+20 \mathrm{~mm} /+10 \mathrm{~mm} ; \mathrm{mMPTA}(\mathrm{D} / \mathrm{S})=82^{\circ} / 83^{\circ} ; \mathrm{mLDTA}(\mathrm{D} / \mathrm{S})=94^{\circ} / 92^{\circ}\right)$; (c) photograph of the same patient with ideally aligned legs as classified by A.A. Artemyev at six-month follow-up; (d) postoperative long-leg standing AP film of the same patient with reference lines being beyond the acceptable limits of normal measuring $\left.\operatorname{MAD}(\mathrm{D} / \mathrm{S})=-16 \mathrm{~mm} /-14 \mathrm{~mm} ; \mathrm{mMPTA}(\mathrm{D} / \mathrm{S})=89^{\circ} / 88^{\circ} ; \mathrm{mLDTA}(\mathrm{D} / \mathrm{S})=88^{\circ} / 89^{\circ}\right) ;(\boldsymbol{e})$ preoperative appearance of the O-shaped legs from orthopaedic group as classified by A.A. Artemyev; $(f)$ preoperative long-leg standing AP film of the same patient with reference lines being beyond the acceptable limits of normal measuring MAD $(D / S)=+15 \mathrm{~mm} /+21 \mathrm{~mm}$; mMPTA $\left.(\mathrm{D} / \mathrm{S})=82^{\circ} / 81^{\circ} ; \mathrm{mLDTA}(\mathrm{D} / \mathrm{S})=92^{\circ} / 91^{\circ}\right) ;(\boldsymbol{g})$ photograph of the same patient with O-shaped legs as classified by A.A. Artemyev at six-month follow-up; $(\boldsymbol{h})$ postoperative long-leg standing AP radiograph of the same patient with reference lines being well within the acceptable limits of normal measuring MAD $(\mathrm{D} / \mathrm{S})=+2 \mathrm{~mm} /+1 \mathrm{~mm}$; $\mathrm{mMTA}(\mathrm{D} / \mathrm{S})=87^{\circ} / 88^{\circ}$; $\left.\operatorname{mLDTA}(\mathrm{D} / \mathrm{S})=90^{\circ} / 91^{\circ}\right)$ 
For each operated segment, the associated duration of the correction (CP) between the day of surgery through the day of accomplished manipulations with the frame, fixation (FP) between the day of accomplished manipulations with the frame through the day of frame removal and frame-on period (FoP) between the day of surgery through the day of frame removal. Therefore, FoP $=\mathrm{CP}+\mathrm{FP}$. The ratios between the CP and FP (CP/FP), the CP and FoP (CP/ $\mathrm{FoP})$ and the FP and FoP (FP/FoP) were calculated for each segment measuring $(\mathrm{CP}+\mathrm{FP}) / \mathrm{FoP}=1$ for each patient. Long-leg standing AP radiographs were performed preoperatively and after frame removal and reviewed in a standard way $[9-12,26]$. Mechanical axis deviation (MAD), mechanical medial proximal tibial angle (mMPTA), mechanical lateral distal tibial angle (mLDTA) were measured. Medial MAD was measured in millimeters and marked with the "-" sign [27]. Measurements of the angles on long-leg standing AP films were produced independently by three orthopaedic surgeons. Further investigations were performed on the averaged measurements. MAD, mMPTA, and mLDTA measured for each patient of both groups were compared with the normal values, calculating the deviation as a scalar value being independent on the direction of deviation and having neither "+" nor "-" sign. Normal range for MAD was $-3 \mathrm{~mm}$ inclusive to $+3 \mathrm{~mm}$ inclusive [12], for mMPTA, $85^{\circ}$ to $90^{\circ}$ [9-12], for mLDTA, $86^{\circ}$ to $92^{\circ}$ [9-12].

The statistical analysis included calculation of the average measurements of six variables characterizing the duration of treatment periods: CP, FP, FoP and the ratios $\mathrm{CP} / \mathrm{FP}, \mathrm{CP} / \mathrm{FoP}$ and $\mathrm{FP} / \mathrm{FoP}$ in the cosmesis and orthopaedic groups. Significant differences in the variables were identified between the two groups with Student $t$ tests for normally distributed variables. The data obtained were summarized as $\mathrm{M} \pm \mathrm{SD}$, where $\mathrm{M}$, means $(\mathrm{M}=\overline{\mathrm{x}})$ and $\mathrm{SD}$, standard deviations $(\mathrm{SD}=\delta / \sqrt{ } \mathrm{n})$ [28]. The values of $\mathrm{M}$ and $\mathrm{SD}$ were specified up to the second decimal place [29]. The average measurements of six variables including MAD, mMPTA, mLDTA and the standard deviations were calculated for both groups using long-leg standing AP radiographs performed before and after treatment. Significant differences in the variables within the group before and after treatment and significant differences in the corresponding variables between the groups were identified in a similar manner. The data obtained were compared with the literature data.

The mean age of patients was 26 (range, 18-32) years in the 'cosmesis' group and 29 (range, 18-43) years in the 'orthopedic' group. Surgeries were performed between 2008 and 2018. All patients have accomplished the treatment. Patients of both groups were operated on by one surgeon, P.N. Kulesh, Ph.D. who followed up on them. Long-leg standing AP radiographs were produced using stitch technology. There were no statistically significant differences in the preoperative measurements of MAD, mMPTA, mLDTA and the deviations between the groups, which confirms the consistency. The study received a favourable opinion from the relevant research ethics committee of the Russian Vreden Research Institute of Traumatology and Orthopedics, Ministry of Health and Social Development of the Russian Federation on 04.03.11.

\section{RESULTS}

There were statistically significant differences in the length of CP between cosmesis and orthopaedic groups measuring $41.93 \pm 3.96$ days and $18.22 \pm 3.05$ days, respectively, and in the duration of FP measuring $97.67 \pm 7.78$ days and $134.89 \pm 9.42$ days, respectively. The differences in the duration of FoP were not significant between cosmesis and orthopaedic groups measuring $139.60 \pm 5.15$ days and $153.00 \pm 8.49$ days, respectively. The mean $\mathrm{CP} /$ $\mathrm{FP}$ ratios in the cosmesis and orthopaedic groups were $0.57 \pm 0.09$ and $0.15 \pm 0.04, \mathrm{CP} / \mathrm{FoP}$ in the groups being $0.31 \pm 0.03$ and $0.12 \pm 0.03$, respectively, $\mathrm{FP} /$ FoP being $0.69 \pm 0.03$ and $0.88 \pm 0.03$, respectively. Differences in $\mathrm{FP} / \mathrm{FoP}, \mathrm{CP} / \mathrm{FoP}$ and $\mathrm{FP} / \mathrm{FoP}$ ratios software were statistically significant in both groups. Data on the length of CP, FP, and FoP reported by different authors during tibial deformity correction in adult patients using transosseous osteosynthesis is presented in Table 1 and Figure 2.

Changes in the MAD measurements from $+17.48 \pm 1.14 \mathrm{~mm}$ to $-6.08 \pm 0.87 \mathrm{~mm}$ in the cosmesis group and from $+19.18 \pm 2.86 \mathrm{~mm}$ to $-0.61 \pm 0.82 \mathrm{~mm}$ in the orthopaedic group (Fig. 3a) as well as the deviations from the norm before and after treatment (from $15.93 \pm 0.81 \mathrm{~mm}$ to $5.63 \pm 0.58 \mathrm{~mm}$ and from $20.18 \pm 1.46 \mathrm{~mm}$ to $1.25 \pm 0.38 \mathrm{~mm}$, respectively) (Fig. 3d) were statistically significant. Changes in mMPTA measurements from $84.90 \pm 0.35^{\circ}$ to $90.80 \pm 0.31^{\circ}$ and from $84.04 \pm 0.76^{\circ}$ to $89.46 \pm 0.54^{\circ}$ before and after treatment (Fig. 3b) were statistically significant. Changes in the deviations of the mMPTA from $1.42 \pm 0.19^{\circ}$ to $1.58 \pm 0.20^{\circ}$ (Fig. 3e) were not statistically significant in the cosmesis group, and from $2.39 \pm 0.41^{\circ}$ to $0.79 \pm 0.24^{\circ}$ (Fig. 3e) 
being statistically significant among orthopaedic patients. Changes in the mLDTA measurements from $90.61 \pm 0.39^{\circ}$ to $88.62 \pm 0.35^{\circ}$ before and after treatment (Fig. 3c) were statistically significant in the cosmesis group. Changes in the mLDTA measurements from $89.09 \pm 0.37^{\circ}$ to $87.68 \pm 0.63^{\circ}$ (Fig. 3c) were not statistically significant in the orthopaedic group. Altered deviations in the mLDTA measurements from $0.98 \pm 0.18^{\circ}$ to $0.62 \pm 0.11^{\circ}$ and from $0.14 \pm 0.01^{\circ}$ to $0.55 \pm 0.12^{\circ}$ ) (Fig. 3f) were not statistically significant in both groups. Comparison of the angles after treatment between the groups showed statistically significant differences in MAD measurements, statistically insifnificant differences in mMPTA values and statistically insignificant differences in mLDTA measurements. The differences in deviations in MAD (Fig. 3d) were statistically significant after treatment; the differences in deviations in mMPTA measurements (Fig. 3e) were not statistically significant after treatment; and the differences in deviations in mLDTA (Fig. 3e) were also not statistically significant after treatment.

The effect of tibial deformity correction in adult patients performed with transosseous osteosynthesis on the correlation of reference lines (MAD and mMPTA) as reported by different authors is presented in Table 2 (mLDTA measurements and deviations are not presented by the authors).

Table 1

Literature data on the duration of CP, FP, FoP, the ratios and the comparison with the own data

\begin{tabular}{|c|c|c|c|c|c|c|c|c|}
\hline & \multicolumn{8}{|c|}{ Authors } \\
\hline & $\begin{array}{c}\text { O.V. Klimov, } \\
\text { K.I. Novikov, } \\
\text { A.M. Aranovich, } \\
2008[30]\end{array}$ & $\begin{array}{c}\text { H.A. Marker, } \\
\text { L.V. Sklyar, } \\
2009[6]\end{array}$ & $\begin{array}{c}\text { A.S. Barinov et } \\
\text { al., 2010 [31] }\end{array}$ & $\begin{array}{c}\text { K. Ashfaq, } \\
\text { S.R. Rozbruch } \\
\text { et al., 2012 } \\
\text { (monolateral frame) } \\
{[32]}\end{array}$ & $\begin{array}{c}\text { K. Ashfaq, } \\
\text { S.R. Rozbruch } \\
\text { et al., 2012 } \\
\text { (TSF-Frame) } \\
\text { [32] }\end{array}$ & $\begin{array}{c}\text { Y.E. Park et al., } \\
2013 \text { [33] }\end{array}$ & $\begin{array}{l}\text { A.A. Artemyev } \\
\text { et al., } 2015 \text { [34] }\end{array}$ & $\begin{array}{l}\text { R.J. Da Cunha, } \\
\text { S.R. Rozbruch } \\
\text { et al., 2020 [35] }\end{array}$ \\
\hline $\begin{array}{l}\text { Number of } \\
\text { segments } \\
\text { operated on }\end{array}$ & 18 & 33 & 246 & 23 & 41 & & 434 & 8 \\
\hline $\begin{array}{l}\text { Age of } \\
\text { patients }\end{array}$ & $15-37$ & $20-29$ & 27.25 & $44(23-73)$ & $39(21-72)$ & 24.8 (SD 5.3) & & 53.37 .53 .29 \\
\hline CP [days] & & $10-40 *$ & $\begin{array}{c}19.70 \pm 3.53 * \\
(14-27)\end{array}$ & $15(8-20)$ & 34 (7-99) & & & \\
\hline FP [days] & & $58.4 \pm 4.4$ & $33.70 *(1953)$ & $101(81-133)$ & $130(95-177)$ & & & \\
\hline FoP [days] & $68.2 \pm 12.7$ & & $\begin{array}{c}57.00 \pm 11.54 \\
(47-93)\end{array}$ & $116^{*}$ & $164 *$ & 173 & $107.14^{*}$ & 97 \\
\hline $\mathrm{CP} / \mathrm{FP}$ & & & $0.58 * \approx 3 / 5$ & $0.15^{*} \approx 1 / 7$ & $0.26^{*} \approx 1 / 4$ & & & \\
\hline $\mathrm{CP} / \mathrm{FoP}$ & & & $0.35^{*} \approx 3 / 8$ & $0.13^{*} \approx 1 / 8$ & $0.21 * \approx 1 / 5$ & & & \\
\hline $\mathrm{FP} / \mathrm{FoP}$ & & & $0.59 * \approx 5 / 8$ & $0.87 * \approx 7 / 8$ & $0.79 * \approx 4 / 5$ & & & \\
\hline $\mathrm{CP}_{\text {auth }} \mathrm{CP}_{\text {cosm }}$ & & & $0.35^{*}$ & $0.36^{*}$ & $0.81 *$ & & & \\
\hline $\mathrm{CP}_{\text {auth } /} \mathrm{CP}_{\text {orth }}$ & & & $0.81 *$ & $0.82 *$ & $1.87^{*}$ & & & \\
\hline $\mathrm{FP}_{\text {auth }} / \mathrm{FP}_{\text {cosm }}$ & & $0.60^{*}$ & $0.35^{*}$ & $1.03 *$ & $1.33^{*}$ & & & \\
\hline $\mathrm{FP}_{\text {auth }} \mathrm{FP}_{\text {orth }}$ & & $0.43^{*}$ & $0.25^{*}$ & $0.75^{*}$ & $0.96^{*}$ & & & \\
\hline $\mathrm{FoP}_{\text {auth }} / \mathrm{FoP}_{\mathrm{cosm}}$ & $0.49^{*}$ & & $0.41 *$ & $0.83^{*}$ & $1.17 *$ & $1.77 *$ & $0.77^{*}$ & $0.69 *$ \\
\hline $\mathrm{FoP}_{\text {auth } /} \mathrm{FoP}_{\text {orth }}$ & $0.45^{*}$ & & $0.37^{*}$ & $0.76^{*}$ & $1.07^{*}$ & $1.28 *$ & $0.70 *$ & $0.63^{*}$ \\
\hline
\end{tabular}

Note $\mathrm{CP}_{\text {ath }}$, length of the correction period as reported by the author; $\mathrm{CP}_{\text {cose }}$, length of the correction period in the cosmesis group; $\mathrm{CP}_{\text {rth }}$, length of the correction period in the orthopaedic group. Mean values (M) were used for calculations. Adjustments for FP and FoP were specified in a similar manner; * values calculated based on the data provided by the authors.

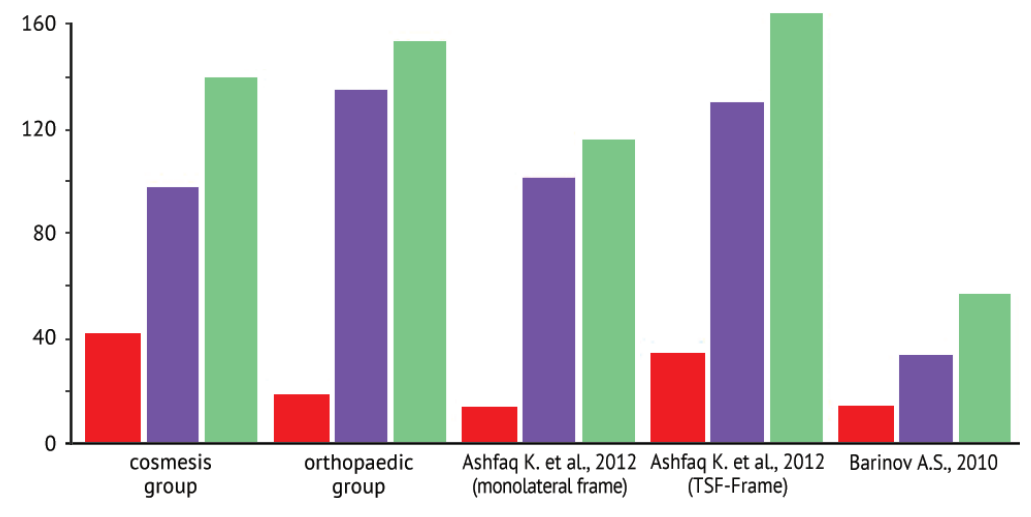

Fig. 2 Correlations in the length of the periods explored (CP, FP, FoP) in the study groups as compared to the data reported by different authors (CP marked as red, FP marked as violet, FoP marked as green) 

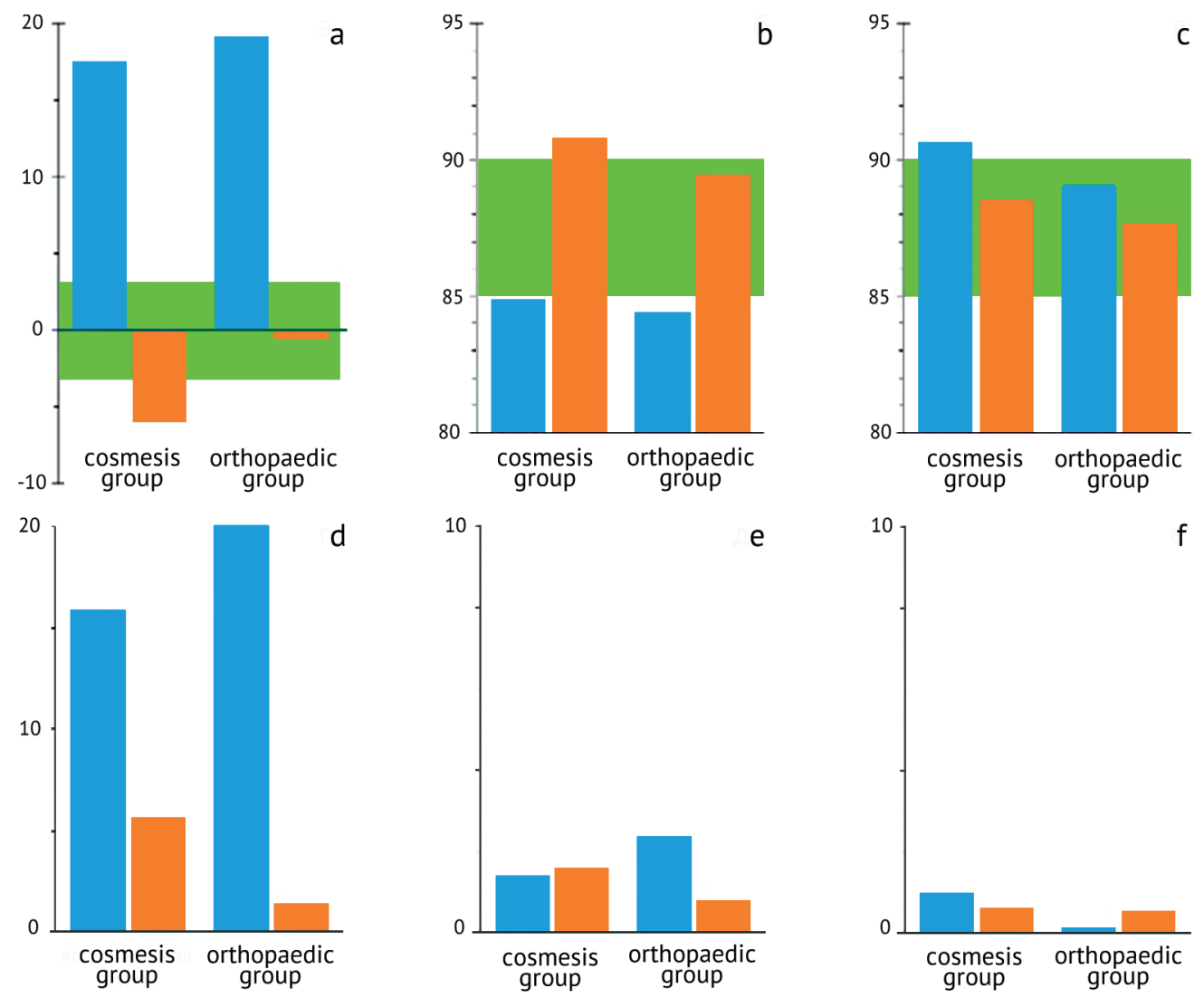

Fig. 3 Changes in the angles measured on long-standing AP radiographs in both groups represented in (a) diagram showing changes in the mean measurements of MAD (hereafter: preoperative angles marked with blue, measurements performed after treatment marked with orange, normal range marked with green ); (b) diagram showing changes in the mean measurements of mMPTA; (c) diagram showing changes in the mean measurements of mLDTA; (d) deviation in MAD measurements, $(\boldsymbol{e})$ deviation in mMPTA measurements; (f) deviation in mLDTA measurements

Table 2

MAD, mMPTA and the deviations measured before and after tibial deformity correction in the upper third of adult patients using transosseous osteosynthesis as reported by different authors (the optimal mMPTA of $85^{\circ}-90^{\circ}$ reported by all authors [9])

\begin{tabular}{|c|c|c|c|c|c|c|}
\hline & \multicolumn{5}{|c|}{ Authors } \\
\hline & & $\begin{array}{l}\text { D. Saragaglia et } \\
\text { al., 2007 [36] }\end{array}$ & \begin{tabular}{|c|} 
K. Ashfaq, \\
S.R. Rozbruch \\
et al., 2012 [32] \\
(monolateral frame) \\
\end{tabular} & $\begin{array}{c}\text { K. Ashfaq, } \\
\text { S.R. Rozbruch } \\
\text { et al., 2012 [32] } \\
\text { (TSF-Frame) } \\
\end{array}$ & $\begin{array}{c}\text { B. Özkul et al., } 2017 \\
{[37]}\end{array}$ & $\begin{array}{l}\text { R.J. Da Cunha, } \\
\text { S.R. Rozbruch } \\
\text { et al., 2020 [35] }\end{array}$ \\
\hline \multicolumn{2}{|c|}{ Number of segments operated on } & 16 & $15 / 8$ & $35 / 6$ & 50 & 8 \\
\hline \multicolumn{2}{|l|}{ Patients' age } & $51.19 \pm 11.15$ & $44(23-73)$ & $39(21-72)$ & $19.4 \pm 6.9(14-39)$ & 53.37 .53 .29 \\
\hline \multirow{3}{*}{ MAD [mm] } & Preoperatively & & $\begin{array}{l}+22 \pm 8 \\
(10-44)\end{array}$ & $\begin{array}{c}+40 \pm 35 \\
(5-155)\end{array}$ & $\begin{array}{c}+37.6 \pm 21.6 \\
(9-98)\end{array}$ & $\begin{array}{c}+31.1 \pm 11.8 \\
(16-42)\end{array}$ \\
\hline & Optimal value & & $0 /-10[38]$ & $0 /-10[38]$ & $+9.7 \pm 6.8[9]$ & $+8 \pm 7[39]$ \\
\hline & After treatment & & $\begin{array}{c}+3 \pm 3(0-7) \\
-5 \pm 3(-2--10)\end{array}$ & $\begin{array}{l}+5 \pm 7(0-30) \\
-4 \pm 3(0-7)\end{array}$ & $\begin{array}{c}+8.4 \pm 12.1 \\
(3-44)\end{array}$ & $\begin{array}{c}+5.5 \pm 5.6 \\
(0-11)\end{array}$ \\
\hline \multirow{2}{*}{$\begin{array}{l}\text { mMPTA } \\
\text { [degrees] }\end{array}$} & Preoperatively & $\begin{array}{l}84.5 \pm 2.19 \\
80(40-87)\end{array}$ & $\begin{array}{c}85 \pm 3 \\
(79-89) \\
\end{array}$ & $80(40-87)$ & $76 \pm 7.2$ & $\begin{array}{l}82.4 \pm 1.3 \\
(81-84)\end{array}$ \\
\hline & After treatment & $\begin{array}{c}90.31 \pm 1.20 \\
(88-92)\end{array}$ & $\begin{array}{c}90 \pm 3 \\
(85-96)\end{array}$ & $88(83-96)$ & $89 \pm 2.5$ & $\begin{array}{c}88.3 \pm 1.9 \\
(86-90)\end{array}$ \\
\hline \multirow{2}{*}{ Deviations } & MAD (M) [mm] & & & & 5.4 & 0.5 \\
\hline & mMPTA (M) [degrees] & 0.31 & 0 & 0 & 0 & 0 \\
\hline
\end{tabular}

\section{DISCUSSION}

Average $\mathrm{CP} / \mathrm{FP}$ ratio in the orthopaedic group was 3.8 times less than that in the cosmesis group. The average CP length duration of $\mathrm{PC}$ was $\approx 1 / 2$ of the FP length in the cosmesis group and $\approx 1 / 7$ of the $\mathrm{FP}$ in the orthopaedic group. Average $\mathrm{CP} / \mathrm{FoP}$ ratio was 2.6 times less in the orthopaedic group than that in the cosmesis group. The average duration of $\mathrm{CP}$ was $\approx 1 / 3$ of the FoP in the cosmesis group and $\approx 1 / 8$ of the FoP in the orthopaedic group. The average FP/FoP ratio was 1.3 times greater in the orthopaedic group than that in the cosmesis group. The average duration of FP was $\approx 2 / 3$ of the FoP 
in the cosmesis group and $\approx 7 / 8$ of the $\mathrm{FoP}$ in the orthopaedic group.

Our own data on CP were comparable with the data of two authors who reported [32] a group of patients treated with monolateral devices with $\mathrm{CP}$ being less than that in the cosmesis and orthopaedic groups, and $\mathrm{CP}$ [31] being less than that in the cosmesis group and greater than that in the orthopaedic group. Data on FP were reported by 3 authors with FP [6, 31] being less than that in the cosmesis and the orthopaedic groups, and one [32] had FP being less than in a group of patients treated with a monolateral device than that in the cosmesis group and greater than that in the orthopaedic group. Data on FoP were provided by 6 authors: in five [30, 31, 32, 34, 35] - had less FoP than the "cosmetic" and "orthopedic" groups ([32] the group of patients who received treatment with a monolateral device), in two $[32,33]-\mathrm{FoP}$ is longer than in both groups ([32] - the group of patients receiving TSF-Frame).

Two authors $[30,31]$ reported the data that would allow us to calculate the $\mathrm{CP} / \mathrm{FP}, \mathrm{CP} / \mathrm{FoP}$ and $\mathrm{FP} / \mathrm{FoP}$ ratios. Four series [30, 33-35] reported FoP only, one [6] reported the $\mathrm{CP}$ and $\mathrm{FP}$ in a form that does not allow calculating the FoP. Calculations of the ratios using the data presented by A.S. Barinov et al. [31] were similar to those detected in the cosmesis group of our series. The ratios calculated in a group of patients treated with a monolateral device presented by K. Ashfaq et al. [32] are on par with the ratios calculated in the orthopaedic group.

MAD measured after treatment were comparable to those reported by two of the four authors [35, 37]. The values being well within acceptable limits of normal [12] were observed in orthopaedic patients of our series. The reported value being closer to the norm was $9.02 \approx 9$ times greater [35]. The optimal MAD value and the range were reported to be different $[9,12,38]$. This can be ascribed to a change in orthopaedic views over time with new studies on the tibial deformity correction reling on updated recommendations for the normal correlations between reference lines. The normal mean of mMPTA after correction was reported by four of the five authors. MMPTA was not within acceptable limits of normal in the cosmesis group of our series and in the reported series [36]. We could not find any information in the medical literature reporting analysis of long standing films of lower limbs that were surgically corrected to change the leg shape for cosmesis. The mean MAD was well within acceptable limits of normal in orthopaedic patients [12] and was closer to the mid range as compared to the reported data; the mean MAD of cosmesis patients was closer to the norm as compared to the one reported [37]. The mean MMPTA was well within acceptable limits of normal in orthopaedic patients as reported in three of the four publications $(75 \%)[32,35,37]$. The mean mMPTA of cosmesis patients was further away from the normal values. There were statistically significant deviations in MAD measured after treatment in the cosmesis and orthopaedic groups $\left(\mathrm{t}_{\mathrm{emp}}=4.20\right.$ with $t_{k r}=1.97$ and 2.61). The mean MAD of cosmesis patients was considered as valgus alignment of the lower limb after treatment.

Similar findings were obtained earlier in a smaller group of patients with MAD measuring $+20.85 \pm 9.08 \mathrm{~mm}$ preoperatively and $8.55 \pm 9.94 \mathrm{~mm}$ after treatment; with mMPTA measuring $86.45 \pm 1.85^{\circ}$ preoperatively and $89.65 \pm 2.30^{\circ}$ after treatment; with mLDTA measuring $89.35 \pm 3.50^{\circ}$ preoperatively and $87.25 \pm 1.63^{\circ}$ after treatment. Statistical data were presented as $\mathrm{M} \pm \delta$, where $\mathrm{M}$ was the mean and $\delta$, the standard deviation [39]. This cannot be explained by an error in performing the correction, because the mean MAD was well within acceptable limits of normal in orthopaedic patients. The mean preopereative mMPTA was less than normal value in both groups and was considered as varus alignment of the tibia. The mean mMPTA measured valgus alignment of the tibia in the cosmesis patients and was well within acceptable limits of normal in orthopaedic patients. Consequently, the valgization performed for cosmesis patients to achieve the leg shape wanted was excessive and finally resulted in valgus alignment of the tibia. The proportion of excessive valgization in cosmesis patients was $1 / 4$ on average of that performed. The average change in MAD in the group was $|17.48 \mathrm{~mm}-(-6.08 \mathrm{~mm})|=23.56 \mathrm{~mm} \approx 24 \mathrm{~mm}$. The average valgization that would normalize MAD is supposed to change it by an average of $\mid 17.48$ $\mathrm{mm}-0 \mathrm{~mm} \mid=17.48 \mathrm{~mm} \approx 18 \mathrm{~mm}(3 / 4$ of $24 \mathrm{~mm})$. This statement cannot be refuted by the review of changes in mMPTA occurred in the group. The mean change in $\mathrm{mMPTA}$ was $\left|84.90^{\circ}-90.80^{\circ}\right|=5.90^{\circ} \approx 6^{\circ}$. Three quarthers of the valgization performed would alter the parameter by an average of $4.43^{\circ} \approx 4.5^{\circ}$ $\left(3 / 4\right.$ of $\left.6^{\circ}\right)$, that is, to $89.33^{\circ}$. The parameter was within acceptable limits of normal. Similarly, if we conditionally assume a normal MAD value of 0 $\mathrm{mm}$, the proportion of "excessive" valgization in orthopaedic patients group would proportion to a $1 / 17$ of that performed (the mean MAD deviation decreased 16 times from resultant correction). 
The limitation of the retrospective comparative study performed was the review of treatment period and long leg standing AP radiographs of patients who were operated on and supervised by a single orthopaedic surgeon. More reliable information can be obtained by conducting a similar multicenter study. The cases of tibial deformity correction were reviewed solely in the coronal plane. Patients who could not achieve the leg shape as wanted were excluded from the cosmesis group with the leg shape scored 3 and below on the five-score Marker-Sklyar grading system [6] modified by Kulesh and Solomin [7]. The study did not include patients who developed complications that required additional surgical interventions.

\section{CONCLUSIONS}

1. The ratio of the average duration of the correction period and the fixation period was $1: 2$ in the cosmesis group and 1:7 in the orthopaedic group. The difference in the length of frame-on periods in both groups was statistically insignificant (Fig. 2).

2. The mean MAD, mMPTA measured to tibial valgus in cosmesis patients who achieved the leg shape as wanted (Fig. 3 a, b; Table 2) and in controls. The mean MAD, mMPTA, mLDTA achieved after the tibial deformity correction were well within acceptable limits of normal in control orthopaedic group (Fig. 3 a-c; Table 2). Therefore, the correction aimed at achieving the leg shape wanted was different from the correction aimed at eliminating tibial malaligment and provided no absence of a deformity.
3. There was a statistically significant decrease in the deviation of MAD by 3 times on average in cosmesis group after treatment, and by 16 times in controls (Fig. 3d). There was no statistically significant decrease in the deviation of the MMPTA in the cosmesis group, and there was a statistically significant decrease in the deviation of the MMPTA in the orthopedic group, by 3 times on average (Fig. 3e).

4. Since the preoperative mean MAD and mMPTA measured to tibial varus in both groups with normal mLDTA, tibial valgus was caused by too much overcorrection/valgization (by $1 / 4$ on average) in cosmesis patients. Consequently, the correction performed facilitated the leg shape for the patient as wanted due to the development of another orthopaedic pathology of tibial valgus.

\section{REFERENCES}

1. Limb Lengthening Forum. [Internet], 2020. Available at: https://www.limblengtheningforum.com/ (accessed 29.07.2020).

2. Korrektsiia nog [Correction of the Lower Limbs]. [Internet], 2020. Available at: https://legscorrection.ru/forum/index.php. (accessed 29.07.2020).

3. Khirurgiia Nizhnikh Konechnostei [Surgery of the Lower Limbs]. [Internet], 2020. Available at: http://varus-valgus.net/ (accessed 29.07.2020).

4. Federalnyi zakon "Ob osnovakh okhrany zdorovia grazhdan v Rossiiskoi Federatsii": tekst s izmeneniiami i dopolneniiami na 2020 god [Federal Law "On the basics of protecting the health of citizens in the Russian Federation ": text with amendments and additions for 2020]. M., Eksmo, 2020, 96 p. (in Russian).

5. Artemev A.A., editor. Esteticheskaia i rekonstruktivnaia khirurgiia nizhnikh konechnostei [Lower limb aesthetic and reconstructive surgery]. Moscow, GEOTAR-Media, 2008, 248 p. (in Russian).

6. Marker N.A. Vybor taktiki i rezultata ortopedicheskoi korrektsii goleni pri kosmeticheskoi deformatsii. Avtoref. dis. ... kand. med. nauk [Choice of the tactics and result of orthopedic correction of the leg in case of cosmetic deformity. Cand. med. sci. diss. abstr.]. Novosibirsk, 2009, 35 p. (in Russian) Available at: http://medical-diss.com/docreader/288249/a?\#?page=1 (accessed: 29.07.2020).

7. Kulesh P.N., Solomin L.N. Korrektsiia formy nog po esteticheskim pokazaniiam (obzor literatury) [Correction of lower limb shape according to aesthetic indications (review of literature)]. Genij Ortopedii, 2013, no. 2, pp. 117-123. (in Russian)

8. Whitaker A.T., Gesheff M.G., Jauregui J.J., Herzenberg J.E. Comparison of PACS and Bone Ninja mobile application for assessment of lower extremity limb length discrepancy and alignment. J. Child. Orthop., 2016, vol. 10, no. 5, pp. 439-443. DOI: 10.1007/s11832-016-0761-5

9. Paley D. Principles of deformity correction. Herzenberg J.E., editor. Springer Science \& Business Media, 2002,806 p.

10. Solomin L.N., editor. Osnovy chreskostnogo osteosinteza apparatom G.A. Ilizarova [Fundamentals of transosseous osteosynthesis with the Ilizarov fixator]. SPb., MORSAR AV, 2005, 544 p. (in Russian)

11. Solomin L.N. The Basic Principles of External Skeletal Fixation Using the Ilizarov and Other Devices. $2^{\text {nd }}$ Edition. Solomin L.N., editor. Milan, Springer-Verlag, 2012, 1593 p. DOI: 10.1007/978-88-470-2619-3_18

12. Standart S.C., Herzenberg J.E., Conway J.D., Siddiqui N.A., McClure P.K. The Art of Limb Alignment. $9^{\text {th }}$ ed. Baltimore, Rubin Institute for Advanced Orthopedics, Sinai Hospital of Baltimore. 2020, 247 p.

13. Feldman D.S., Madan S.S., Koval K.J., van Bosse H.J., Bazzi J., Lehman W.B. Correction of tibia vara with six-axis deformity analysis and the Taylor Spatial Frame. J. Pediatr. Orthop., 2003, vol. 23, no. 3, pp. 387-391.

14. Programma modelirovaniia Legscorrection [Legscorrection Modelling Program]. Available at: https://legscorrection.ru/prog.php (accessed 29.07.2020).

15. Kaplunov O.A., Kaplunov A.G., Shevtsov V.I. Kosmeticheskaia korrektsiia formy $i$ dliny nog [Cosmetic correction of the lower limb shape and length]. M., GEOTAR-Media, 2010, 160 p. (in Russian)

16. Coventry M.B. Osteotomy of the upper portion of the tibia for degenerative arthritis of the knee. A preliminary report. J. Bone Joint Surg. Am., 1965, vol. 47, pp. 984-990.

17. Miniaci A., Ballmer F.T., Ballmer P.M., Jakob R.P. Proximal tibial osteotomy. A new fixation device. Clin. Orthop. Relat. Res., 1989, no. 246, pp. 250-259.

18. Lobenhoffer P., Agneskirchner J.D. Improvements in surgical technique of valgus high tibial osteotomy. Knee Surg. Sports Traumatol. Arthrosc., 2003, vol. 11, no. 3, pp. 132-138. DOI: 10.1007/s00167-002-0334-7

19. Segev E. Updates on preoperative planning, limb deformity analysis and surgical correction for the growing children: EPOS Meeting Marseille 2015 proceedings. J. Child. Orthop., 2016, vol. 10, no. 6, pp. 493-498. DOI: 10.1007/s11832-016-0795-8

20. Hambardzumyan V., Herzenberg J.E. Bone Ninja app as a body image simulation tool for shared decision-making. J. Limb Lengthen. Reconstr., 2019, vol. 5, no. 2, pp. 105-110. URL: https://www.jlimblengthrecon.org/text.asp?2019/5/2/105/274579. 
21. Shevtsov V.I., Nemkov V.A., Skliar L.V. Apparat Ilizarova. Biomekhanika [The Ilizarov fixator. Biomechanics.]. Kurgan, Periodika, 1995 , 165 p. (in Russian)

22. Caton J., Dumont P., Bérard J., Michel C.R. Etude des résultats à moyen terme d'une série de 33 allongements des membres inférieurs selon la technique de $\mathrm{H}$. Wagner [Study of the medium-term results of a series of 33 lengthening of the lower limbs according to the technique of $\mathrm{H}$. Wagner]. Rev. Chir. Orthop., 1985, vol. 71, pp. 44-48.

23. Paley D. Problems, obstacles, and complications of limb lengthening by the Ilizarov technique. Clin. Orthop. Relat. Res., 1990, no. 250, pp. 81-104.

24. Donnan L.T., Saleh M., Rigby A.S. Acute correction of lower limb deformity and simultaneous lengthening with a monolateral fixator. J. Bone Joint Surg. Br., 2003, vol. 85, no. 2, pp. 254-260. DOI: 10.1302/0301-620x.85b2.12645

25. Vilenskii V.A., Pozdeev A.A., Zubairov T.F., Zakharian E.A., Pozdeev A.P. Lechenie detei s deformatsiiami dlinnykh trubchatykh kostei nizhnikh konechnostei metodom chreskostnogo osteosinteza s ispolzovaniem apparata Orto-SUV: analiz 213 sluchaev [Treatment of children with deformities of the lower limb long tubular bones by transosseous osteosynthesis method using Ortho-SUV Frame: analysis of 213 cases]. Ortopediia, Travmatologiia i Vosstanovitelnaia Khirurgiia Detskogo Vozrasta, 2016, vol. 4, no. 4, pp. 21-32. (in Russian) DOI: 10.17816/PTORS4421-32

26. Jamali A.A., Meehan J.P., Moroski N.M., Anderson M.J., Lamba R., Parise C. Do small changes in rotation affect measurements of lower extremity limb alignment? J. Orthop. Surg. Res., 2017, vol. 12, no. 1, pp. 77. DOI: 10.1186/s13018-017-0571-6

27. Sabharwal S., Badarudeen S., McClemens E., Choung E. The effect of circular external fixation on limb alignment. J. Pediatr. Orthop., 2008 , vol. 28, no. 3, pp. 314-319. DOI: 10.1097/BPO.0b013e3181653ba2.

28. Sokal R.R., Rolf F.J. Biometry: The Principles and Practices of Statistics in Biological Research. $3^{\text {rd }}$ ed. New York, W.H. Freeman \& Co, 1994, $880 \mathrm{p}$.

29. Chernchujit B., Tharakulphan S., Prasetia R., Chantarapanich N., Jirawison C., Sitthiseripratip K. Preoperative planning of medial opening wedge high tibial osteotomy using 3D computer-aided design weight-bearing simulated guidance: Technique and preliminary result. J. Orthop. Surg. (Hong Kong), 2019, vol. 27, no. 1, pp. 2309499019831455 . DOI: $10.1177 / 2309499019831455$.

30. Klimov O.V., Novikov K.I., Aranovich A.M. Modelirovanie formy nizhnikh konechnostei u patsientov s varusnoi deformatsiei golenei [Modeling the shape of the lower limbs in patients with varus deformity of the legs]. Genij Ortopedii, 2008, no. 2, pp. 50-53. (in Russian)

31. Barinov A.S., Vorobev A.A., Zaitsev S.S., Tsarkov P.S. Kosmeticheskie aspekty operativnoi korrektsii displasticheskikh varusnykh deformatsii nizhnikh konechnostei [Cosmetic aspects of the surgical correction of dysplastic varus deformities of the lower limbs]. Klinicheskaia Meditsina, 2010, no. 4, pp. 57-60. (in Russian)

32. Ashfaq K., Fragomen A.T., Nguyen J.T., Rozbruch S.R. Correction of proximal tibia varus with external fixation. J. Knee Surg., 2012, vol. 25, no. 5, pp. 375-384. DOI: 10.1055/s-0031-1299659

33. Park Y.E., Song S.H., Kwon H.N., Refai M.A., Park K.W., Song H.R. Gradual correction of idiopathic genu varum deformity using the Ilizarov technique. Knee Surg. Sports Traumatol. Arthrosc., 2013, vol. 21, no. 7, pp. 1523-1529. DOI: 10.1007/s00167-012-2074-7

34. Artemev A.A., Zagorodnii N.V., Ivashkin A.N., Bytdaev Z.M., Abakirov M.D. Sovremennoe sostoianie esteticheskoi ortopedii nizhnikh konechnostei: problemy i perspektivy [Modern status of aesthetic orthopaedics of the lower limbs: problems and prospects]. Klinicheskaia Praktika, 2015, no. 1, pp. 4-9. (in Russian)

35. Da Cunha R.J., Kraszewski A.P., Hillstrom H.J., Fragomen A.T., Rozbruch S.R. Biomechanical and functional improvements gained by proximal tibia osteotomy correction of genu varum in patients with knee pain. HSS J., 2020, vol. 16, no. 1, pp. 30-38. DOI: 10.1007/s11420-019-09670-6

36. Saragaglia D., Rubens-Duval B., Chaussard C. Doubles ostéotomies assistées par ordinateur dans les grands genu varum: résultats préliminaires à propos de 16 cas [Computer-assisted combined femoral and tibial osteotomy for severe genu varum: early results in 16 patients]. Rev. Chir. Orthop. Reparatrice Appar. Mot., 2007, vol. 93, no. 4, pp. 351-356. (in French) DOI: 10.1016/s0035-1040(07)90276-7

37. Özkul B., Çamurcu Y., Sokucu S., Yavuz U., Akman Y.E., Demir B. Simultaneous bilateral correction of genu varum with Smart Frame. J. Orthop. Surg. (Hong Kong), 2017, vol. 25, no. 2, pp. 2309499017713915 . DOI: 10.1177/2309499017713915

38. Coventry M.B., Ilstrup D.M., Wallrichs S.L. Proximal tibial osteotomy. A critical long-term study of eighty-seven cases. J. Bone Joint Surg. Am., 1993, vol. 75, no. 2, pp. 196-201. DOI: 10.2106/00004623-199302000-00006

39. Solomin L.N., Kulesh P.N. Analiz pokazatelei referentnykh linii i uglov pri izmenenii formy nog s ispolzovaniem chreskostnogo osteosinteza (predvaritelnoe soobshchenie) [Analysis of the values of reference lines and angles when changing the shape of the legs using transosseous osteosynthesis (a preliminary report)]. Travmatologiia i Ortopediia Rossii, 2011, no. 2, pp. 62-69. (in Russian)

Received: 16.09 .2020

\section{Information about authors:}

1. Pavel N. Kulesh, M.D., Ph.D.,

City Hospital of St. George the Great Martyr, Saint Petersburg, Russian Federation,

Email: kulesh_pavel@mail.ru

2. Leonid N. Solomin, M.D., Ph.D., Professor,

Vreden National Medical Research Center of Traumatology and Orthopedics, Saint Petersburg, Russian Federation,

Saint-Petersburg State University, Saint Petersburg, Russian Federation,

Email: solomin.leonid@gmail.com 